\title{
DA IDEIA AO CONCEITO DE PRODUTO: o uso de técnicas criativas combinadas para auxiliar no processo de desenvolvimento de novos produtos de design.
}

\author{
Stella Lisboa Sapper \\ Universidade Federal do Rio Grande do Sul \\ stellasapper@gmail.com \\ Felipe Schneider Viaro \\ Universidade Federal do Rio Grande do Sul \\ felipesviaro@gmail.com \\ Régio Pierre da Silva \\ Universidade Federal do Rio Grande do Sul \\ regio@ufrgs.br \\ Fábio Gonçalves Teixeira \\ Universidade Federal do Rio Grande do Sul \\ fabiogt@ufrgs.br
}

\begin{abstract}
Resumo: A criatividade é um fator essencial para a competitividade dos produtos e o sucesso das empresas. Existe uma série de técnicas criativas que podem ser utilizadas por equipes de projeto de produto. Porém, ocorrem dificuldades na aplicação sistemática dessas técnicas no momento de gerar as concepções de projeto. O objetivo deste trabalho é discutir o uso de técnicas criativas para a geração de ideias de produtos durante o Processo de Desenvolvimento de Produtos (PDP). Foi realizado um estudo experimental por meio do desenvolvimento de um produto que auxilie no transporte de crianças. $O$ desenvolvimento do produto foi realizado até a etapa de projeto conceitual. Para isso, foi utilizado o jogo Creative Sketch na geração de ideias, assim como, técnicas de avaliação e seleção de concepções de projeto para eleger as concepções mais adequadas aos requisitos de projeto. A utilização do jogo possibilitou a geração de 72 ideias em um curto período de tempo. Além do jogo, utilizaram-se o método da síntese funcional e a técnica da matriz morfológica para a geração de alternativas, assim como o método de Pugh para a seleção das melhores alternativas. Como resultado desse processo obtiveram-se duas concepções de produto que atenderam aos requisitos de projeto estabelecidos.
\end{abstract}

Palavras-chave: Criatividade, Técnicas para a geração de ideias, PDP, Jogo, Seleção de concepções. 


\begin{abstract}
Creativity is a key factor for the competitiveness of products and business success. There are a number of creative techniques that can be used by product design teams. However, there are difficulties in the systematic application of these techniques while generating the project conceptions. The objective of this paper is to discuss the use of creative techniques for generating product ideas during the Product Development Process (PDP). An experimental study was conducted by developing a product that assists in the transport of children. The development was carried out until the stage of conceptual design. For this, the game Creative Sketch was used in the generation of ideas. Technical evaluation and selection of project concepts were also used to elect the conceptions most appropriate to the project requirements. The game allowed the generation of 72 ideas in a short period of time. The method of functional synthesis and the technique of morphological matrix were also used for generating ideas. The Pugh method was used for the selection of alternatives. As a result of this process were obtained two conceptions of product that met the requirements established project.
\end{abstract}

Key-words: Creativity, Creative techniques, PDP, Game, Selection of alternatives.

\title{
1. INTRODUÇÃO
}

Design e criatividade são temas que comumente aparecem juntos em estudos de diferentes perspectivas a respeito da resolução de problemas e da geração de novas ideias. A criatividade é tão intimamente relacionada ao design que muitos autores (CROSS, 1997; CRILLY, 2010; FRIEDMAN, 2000) ressaltam que os processos criativos ocupam grande parcela do tempo na formação de profissionais em design.

A atividade de design envolve projetos e novas ideias, e para inovar é preciso usar a criatividade. A criatividade é essencial em todos os estágios do projeto em design. A maior parte dos projetos é dedicada as variantes de um produto, incluindo o redesenho ou o aperfeiçoamento de produtos existentes no mercado, porém isso não torna a criatividade menos importante durante esse processo (BAXTER, 2000).

A criatividade pode ser colocada em prática através do uso de diversas técnicas para o seu estimulo, as quais frequentemente são utilizadas na etapa de geração de ideias para o produto. Como o design trabalha com problemas complexos, esses são passíveis de inúmeras soluções. Essa complexidade dos problemas de design exige uma sistematização do processo criativo e pode ser dividido entre as seguintes etapas: preparação; geração de ideias; seleção da ideia e revisão do processo criativo (BAXTER, 2000).

Para Back et al. (2008) a etapa de geração de ideias se encontra no projeto informacional do Processo de Desenvolvimento de Produtos (PDP), enquanto que a geração de concepções e alternativas encontra-se na etapa de projeto conceitual. Para este trabalho foi utilizado o jogo Creative Sketch visando à geração de ideias pra um problema de design. Sua aplicação ocorreu durante as aulas da disciplina de Processo de Geração e Seleção de Concepções de Projeto da Pós-Graduação em Design (PGDesign) da Universidade Federal do Rio Grande do Sul (UFRGS). 


\section{DESIGN E CRIATIVIDADE}

No âmbito do design, Simon (1996), em "A ciência do artificial", 1ạ edição datando de 1969, introduziu a ideia do design como um processo racional de resolução de problemas. Com essa ideia Simon (1996) conseguiu introduzir uma base de conhecimento para a construção das metodologias de design existentes. A teoria construída por ele atesta que, para criar um artefato, não é necessário o conhecimento pleno do funcionamento interno deste artefato, desde que exista um conhecimento do objetivo para o qual ele será usado. A atividade do designer é, segundo Simon (1996), adaptar a interface do objeto entre o funcionamento interno e externo. Assim, se existe uma falha nesta adaptação, ou seja, se o ambiente interno não corresponde ao externo, o comportamento apresentado pelo artefato será limitado ao seu ambiente interno.

Após quinze anos do lançamento das ideias de Simon, Schön (1983 apud DORST; DIJKHUIS, 1995) descreveu o design como um processo de "reflexão na ação". A teoria de Schön foi uma reação à teoria da resolução de problemas de Simon, então considerada uma teoria defasada. Refletir durante o processo faz com que se aprenda com o problema e a geração de alternativas seja enriquecida (DORST; DIJKHUIS, 1995, p. 261).

Segundo Santana et al. (2006), o conhecimento novo depende de um processo ativo de acomodação entre este e o conhecimento pré-existente na memória. Assim, pode-se dizer que cada nova "ação reflexiva" gera um novo conhecimento, que permite que os novos projetos sejam realizados com uma maior base de conhecimento. Esse conhecimento pré-existente é o que Schön (1983) defende como a base da profissão do designer e, segundo Sweller et al. (1998), é nesse conhecimento já estabelecido que os designers buscam informações para seus novos projetos. Comparando as experiências já feitas, o projetista pode gerar novas soluções para problemas que vierem a acontecer.

Crilly (2010) ressalta duas situações sobre o processo do design, onde se pode descrevê-lo a partir dos insights, dos "saltos criativos", ou do aperfeiçoamento de ideias anteriores. "A primeira promove a noção repentina, de saltos revolucionários para frente, enquanto a segunda se concentra em como as ideias são construídas de forma incremental sobre aquelas que as precedem" (CRILLY, 2010, p. 56).

Podem-se relacionar as considerações de Crilly (2010) com dois tipos de produtos provenientes de processos criativos: a criatividade radical e a incremental. Os "saltos criativos" estão mais ligados à criatividade radical. Magjar et al. (2011) concluíram que o investimento em criatividade, em qualquer corporação, a disposição para assumir novos riscos e o grande comprometimento com a carreira por parte dos profissionais estão associados com a criatividade radical, enquanto a presença de pessoas criativas no trabalho e a identificação organizacional associam-se mais com a criatividade incremental.

No âmbito do design, os saltos criativos podem gerar mudanças radicais. Cross (1997) acredita que o design criativo não pode somente ser caracterizado pelos projetos provenientes dos saltos criativos, mas também por todo projeto que gere mudança, seja ela radical ou não. Essas mudanças são deslocamentos no espaço através das soluções de projeto (CROSS, 1997, p. 428). Porém, Cross (1997) conclui que o insight do design criativo pode ser considerado mais como uma "ponte criativa" do que um "salto". 
Muitas vezes o design criativo está mais relacionado ao produto da criatividade do que com o processo de criatividade propriamente dito. "Alguns acreditam que todo o projeto, por sua natureza, é criativo. No entanto há momentos em que o designer vai gerar uma proposta particularmente nova, [...] e o nível de criatividade pode ser confirmada por uma avaliação em grupo" (CROSS, 1997, p. 427).

Friedman (2000) define o designer como uma pessoa múltipla, a qual muitas vezes não consegue ter todas as habilidades que ele necessita. A necessidade de diferentes alternativas para a resolução de problemas de design coloca o designer como um gerenciador de tarefas, onde ele deve ter a capacidade de analisar as necessidades de determinado projeto e designar funções a sua equipe, pois o pensamento sistêmico e em rede demonstrou ser uma maneira eficaz de aperfeiçoar os resultados.

\section{PDP: DA GERAÇÃO DE IDEIAS À CONCEPÇÃO DE PRODUTO}

O modelo do Processo de Desenvolvimento Integrado de Produtos (PRODIP), desenvolvido por Romano (2003 apud BACK et al., 2008), auxilia na compreensão deste processo e possibilita aplicações práticas e didáticas. O modelo contribui para a inovação e o desenvolvimento de novos produtos. O PRODIP é composto de três macrofases que são decompostas em oito fases. As fases são decompostas em atividades e, estas, divididas em tarefas. A Figura 1 apresenta a visão geral do processo, o detalhamento das fases e, abaixo delas, os resultados de cada fase. Com este nível de detalhamento é possível realizar o desenvolvimento de produtos de forma eficaz e compreensível a todos os envolvidos no projeto.

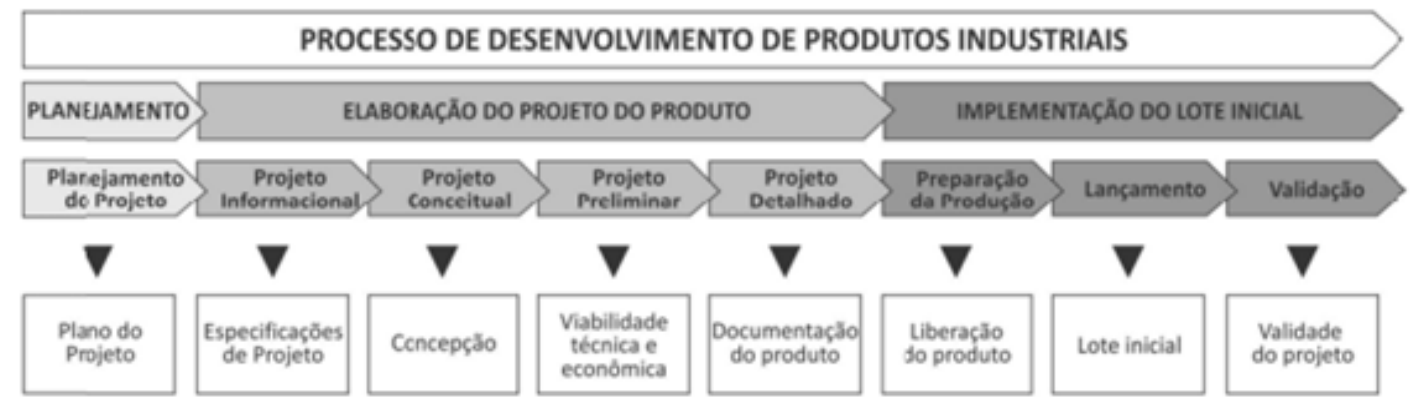

Figura 1 - Etapas do PRODIP.

Fonte: Back et al. (2008, p. 70).

A ideia do produto é um dos principais resultados da fase de planejamento de produtos e serve para auxiliar na tomada de decisões da empresa quanto à realização ou não do projeto. A ideia, ou conceito do produto, sintetiza os principais atributos do produto e depende da perspectiva da visão ou linguagem que se queira dar. Alguns setores possuem uma linguagem que privilegia a técnica, enquanto outros possuem linguagens mais conceituais (setor automobilístico e setor de moda). A ideia pode ser representada como descrição de características do produto, descrição funcional do produto ou descrição de princípios de funcionamento do produto, ou ainda, uma combinação destes. Pode ser comunicada na forma de textos ou imagens (BACK et al., 2008).

É importante diferenciar os conceitos de ideia de produto e concepção de produto. Segundo Back et al. (2008) a ideia de produto é um dos resultados do planejamento de produto enquanto que a concepção de produto é uma ideia que 
passou por um processo de refinamento e encontra-se na etapa de projeto conceitual. O mesmo autor relaciona o número necessário de ideias geradas com o número de produtos lucrativos: para cada 100 ideias geradas, 18 chegam ao projeto conceitual, tornando-se concepções de produto e, dessas, apenas 5 tornam-se produtos lucrativos.

Para Back et al. (2008), é na etapa de projeto informacional que se definem as especificações do projeto de produto. Para identificar os norteadores do projeto conceitual, primeiro são identificadas as necessidades do cliente, que são transformadas em requisitos do usuário e, após, em requisitos de projeto. Estes utilizam linguagem técnica e objetiva, e consideram atributos funcionais, ergonômicos, de segurança, de confiabilidade, estéticos, legais, entre outros. Com posse dessas informações, pode ser realizada uma pesquisa comparativa de mercado para verificar se os produtos existentes atendem às especificações do projeto (BACK et al., 2008).

Ainda no projeto informacional é feita a geração de ideias. Essa etapa envolve processo criativo, mas também a coleta e a classificação das ideias existentes. Métodos e técnicas auxiliam nessa etapa, como a matriz de tecnologias versus necessidades e o método de análise do estilo de vida. Após o projeto informacional ocorre o projeto conceitual. Nele acontece o processo de geração de concepções, ou alternativas, onde os requisitos de projeto são levados em consideração (BACK et al., 2008).

O projeto conceitual objetiva desenvolver a concepção do produto, demonstrando de que forma o novo produto atingirá aos benefícios básicos do consumidor e se diferenciará da concorrência. Para cumprir esta etapa com sucesso, deve ser gerado o maior número possível de alternativas e selecionar a melhor destas. O primeiro a se fazer no projeto conceitual é definir o espaço do problema, que é o campo de atuação da atividade de design, delimitado pelas restrições dos problemas, e que separa as soluções existentes da meta a ser atingida. Com esse aspecto examinado, pode-se verificar se o planejamento de produto está adequado. Depois, é realizada a geração de ideias e, por último, a seleção de ideias. Existe uma série de técnicas disponíveis para executar os últimos procedimentos (BAXTER, 2000).

Para Back et al. (2008), o ponto de partida do projeto conceitual é a identificação da estrutura funcional do produto, de sua função global e subfunções. Após o estudo da estrutura funcional identificada, são geradas concepções alternativas de projeto. Por fim, é realizada a seleção dentre as alternativas considerando: as especificações do projeto; o custo meta; riscos de desenvolvimento; e as metas de qualidade, segurança e dependabilidade.

As técnicas criativas utilizadas para a geração de conceitos são capazes de aumentar consideravelmente o número de concepções geradas exclusivamente pela intuição e imaginação. Alguns efeitos obtidos pela aplicação dessas técnicas são: a decomposição do projeto conceitual em seus aspectos elementares (abstração do conceito); e a analise dos aspectos distintos do projeto conceitual pelo uso de métodos de raciocínio estruturado (BAXTER, 2000).

No projeto de produtos a geração e a seleção de ideias devem ocorrer em dois momentos distintos do processo. Nem sempre é simples fazer a avaliação de uma ideia antes que ela seja desenvolvida no projeto conceitual. Por isso é ideal que as ideias sejam avaliadas posteriormente ao processo de geração das mesmas. O julgamento 
posterior melhora a fluidez na fase de criação durante a aplicação das ferramentas para a geração de ideias (BAXTER, 2000).

\section{MÉTODO DE TRABALHO}

Este trabalho foi desenvolvido em três etapas principais: geração de ideias de produto e exploração das técnicas criativas através do jogo Creative Sketch; geração de concepções de produto a partir das técnicas da síntese funcional e matriz morfológica; seleção das concepções de produto a partir da matriz de Pugh.

\subsection{Aplicação sistemática das técnicas criativas}

Para a geração de ideias de produto utilizou-se o jogo Creative Sketch, desenvolvido por Cardozo (2012) no PGDesign da UFRGS. Esse jogo encontra-se em processo de registro industrial e pode ser visto como um artefato criativo para auxiliar equipes na resolução de problemas de projeto. Cardozo (2012) elaborou sua proposta sistematizando um conjunto de técnicas criativas adequadas à resolução de problemas desestruturados, que é o caso de projetos de produto, visando à interação entre grupos. Este jogo responde a uma necessidade de alinhamento das técnicas criativas com os fatores emocionais para estimular a criatividade de equipes de projeto (CARDOZO, 2012).

No jogo, são utilizadas sequencialmente as seguintes técnicas: brainstorming visual; gatilho de ideias; técnica dos princípios inventivos (TRIZ); e seis chapéus. Cada técnica é aplicada em determinada etapa do jogo com um objetivo. Todos os grupos devem desenvolver ideias para cada etapa:

- A primeira etapa objetiva gerar o maior número de ideias possível com o brainstorming visual, estimulando a exploração de alternativas e iniciando a discussão sobre as soluções geradas;

- A segunda etapa estimula o raciocínio e o humor dos grupos por meio do gatilho de ideias, que leva a equipe a utilizar, na geração de alternativas, conceitos que não possuem relação direta com o problema de projeto;

- Na terceira etapa, os grupos utilizam os princípios inventivos na geração de ideias, estimulando a aplicação de princípios de solução comumente encontrados em projetos de produto;

- Na quarta etapa, a aplicação da técnica dos seis chapéus, especificamente o chapéu preto (aspecto crítico), permite que os grupos emitam opiniões sobre a viabilidade e eficácia das duas melhores ideias de cada grupo. No fim desta etapa, cada grupo passa à fase seguinte com sua melhor ideia.

- Na quinta e última etapa aplica-se novamente a técnica dos seis chapéus, porém utilizam-se todos os chapéus (aspectos informativo, intuitivo, crítico, positivo, inovativo e processual) para avaliar a melhor ideia de cada grupo. O grupo com a pontuação mais alta segue o processo projetual para o desenvolvimento do produto.

O jogo foi desenvolvido durante quatro sessões de três horas como proposta da disciplina de Processo de Geração e Seleção de Concepções de Projeto, no PGDesign da UFRGS, entre maio e junho de 2013. Foi sugerido pelo coordenador do jogo o seguinte problema de projeto: desenvolver um artefato que auxilie pais e/ou responsáveis no transporte de crianças de até 18 meses, em trajetos de curta distância, como por exemplo, da casa dos pais até a creche, em diferentes meios. Seis 
grupos, de três pessoas cada, participaram do jogo. Para cada grupo foi designada uma cor. Neste trabalho, será enfatizado o processo do grupo laranja, do qual fazem parte os autores. O jogo foi desenvolvido até a quarta etapa, pois o processo de projeto teve sequência utilizando técnicas criativas sistematizadas (ver itens 4.2 e 4.3).

Na primeira etapa foram geradas oito ideias com propostas variadas, buscando eliminar julgamentos iniciais e critérios fixados. Destas, as cinco melhores foram selecionadas para o tabuleiro. Na segunda etapa, o conceito recebido para utilizar na geração de ideias foi gravidade. Dessa forma, foram geradas e melhoradas ideias que diminuíssem ou utilizassem o peso do produto para algum propósito. Na terceira etapa, utilizaram-se os princípios do contrapeso, do amortecimento e da dinamicidade para gerar três ideias de produto. Na quarta etapa, selecionaram-se as duas melhores ideias para serem avaliadas pelos demais grupos.

$O$ resultado final do jogo foi um total de 72 ideias geradas pelos seis grupos. A progressão das etapas pode ser vista na área em laranja da Figura 2, na qual a base representa a primeira etapa e, o topo, a última. A ideia vencedora do grupo laranja está em destaque na Figura 2 e é desenvolvida posteriormente no trabalho.

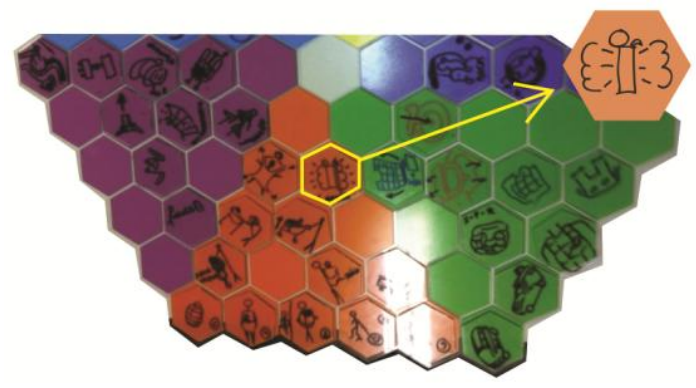

Figura 1 - Resultado do jogo Creative Sketch.

Fonte: Elaborado pelos autores, com base na pesquisa realizada.

\subsection{Geração de concepções de projeto}

A ideia gerada na etapa anterior carecia de especificações técnico-funcionais. Com isso, foi realizada uma nova geração a partir do método sistemático da matriz morfológica com maior detalhamento das especificações de projeto. A matriz morfológica permite a geração sistemática de novas ideias de produto a partir da combinação de princípios de solução que compõem a matriz. O método da matriz morfológica foi baseado no procedimento proposto por Back et al. (2008): identificação da função global do sistema e suas interfaces; decomposição da função global em funções elementares; preenchimento da matriz morfológica com as funções e princípios de solução; combinação de princípios para gerar concepções de produto.

A função global do sistema de produto foi identificada como transportar a criança até a creche; as interfaces foram reconhecidas como a pessoa que transportará a criança e o meio (i.e., rua, carros, ônibus).

Para auxiliar na decomposição da função global do sistema de produto, Back et al. (2008) sugerem descrever o fluxo de informações do processo de uso do produto. 0 fluxo se dá na seguinte ordem: o usuário acomoda a criança no produto; apanha os objetos da criança e sai de casa; caminha até a parada e espera pelo ônibus; embarca no ônibus; passa pela catraca e senta-se em um banco ou fica em pé; desce do ônibus; caminha até a creche. 
A partir deste fluxo de informações, realizou-se a decomposição da função global do sistema de produto em funções parciais e elementares. Back et al. (2008) recomendam que as funções parciais sejam decompostas até o nível em que seja possível encontrar princípios de solução para cada função elementar. A Figura 3 apresenta a função global na primeira linha, as funções parciais na segunda linha, e as funções elementares na terceira linha.

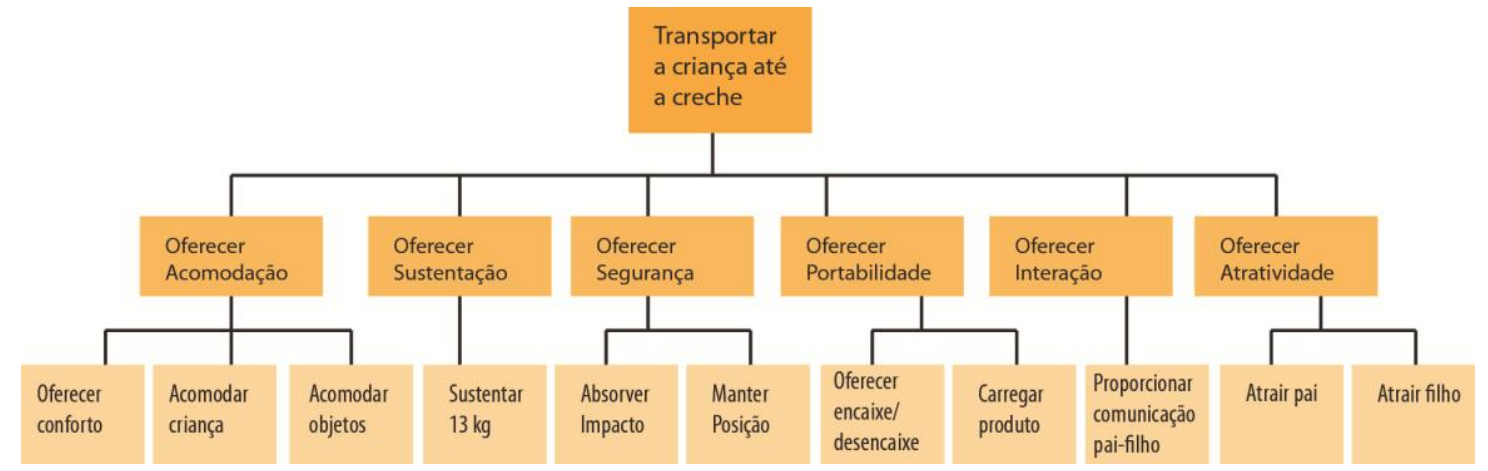

Figura 2 - Decomposição da função global do sistema de produto.

Fonte: Elaborado pelos autores, com base na pesquisa realizada.

A partir da identificação das funções do produto, a matriz morfológica é preenchida com as funções parciais na primeira coluna (acomodação, sustentação, etc.), as funções elementares na segunda coluna (oferecer conforto, acomodar criança, etc.) e os respectivos princípios de solução, encontrados para estas funções, nas demais colunas (Figura 4). Esta matriz foi preenchida com as linguagens textual e visual, pois alguns princípios são melhores explicitados por palavras e outros por imagens.

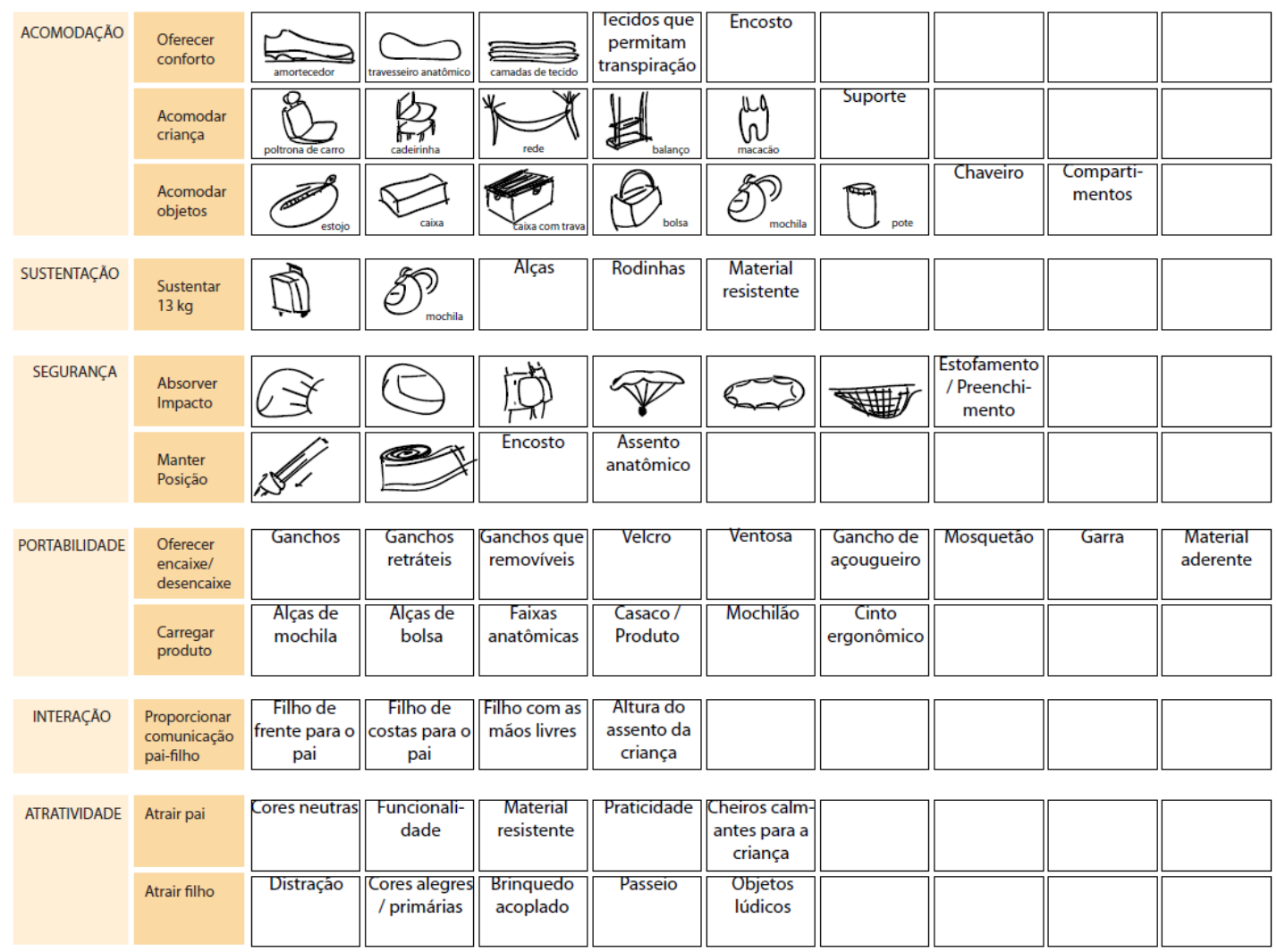

Figura 3 - Matriz morfológica preenchida.

Fonte: Elaborado pelos autores, com base na pesquisa realizada. 
Foram geradas 15 ideias de produto combinando os diversos princípios de solução. As possibilidades de geração com esta ferramenta são praticamente ilimitadas. Porém, verificou-se que muitas das alternativas geradas continham sistemas incompatíveis (o sistema de sustentação não comportava o sistema de acomodação), ou então resultavam em produtos com problemas estético-funcionais.

Para solucionar a dificuldade observada, o espaço do problema foi revisitado, conforme aconselha Baxter (2000). Assim, foram definidos os requisitos de projeto para auxiliar na geração de concepções e, posteriormente, na seleção das alternativas. Os seguintes requisitos de projeto foram declarados: segurança; conforto; facilidade de uso; montagem e desmontagem; facilidade de manutenção; boa aparência; viabilidade técnica; baixo custo; facilidade de armazenagem; facilidade de transporte; fator sustentável.

Após nova etapa de geração, quatro ideias foram identificadas como principais e foram desenvolvidas até tornarem-se concepções de produto. A Figura 5 apresenta as concepções S1 e S2 juntas aos princípios de solução utilizados em seu desenvolvimento. A Figura 6 apresenta as soluções S3 e S4.
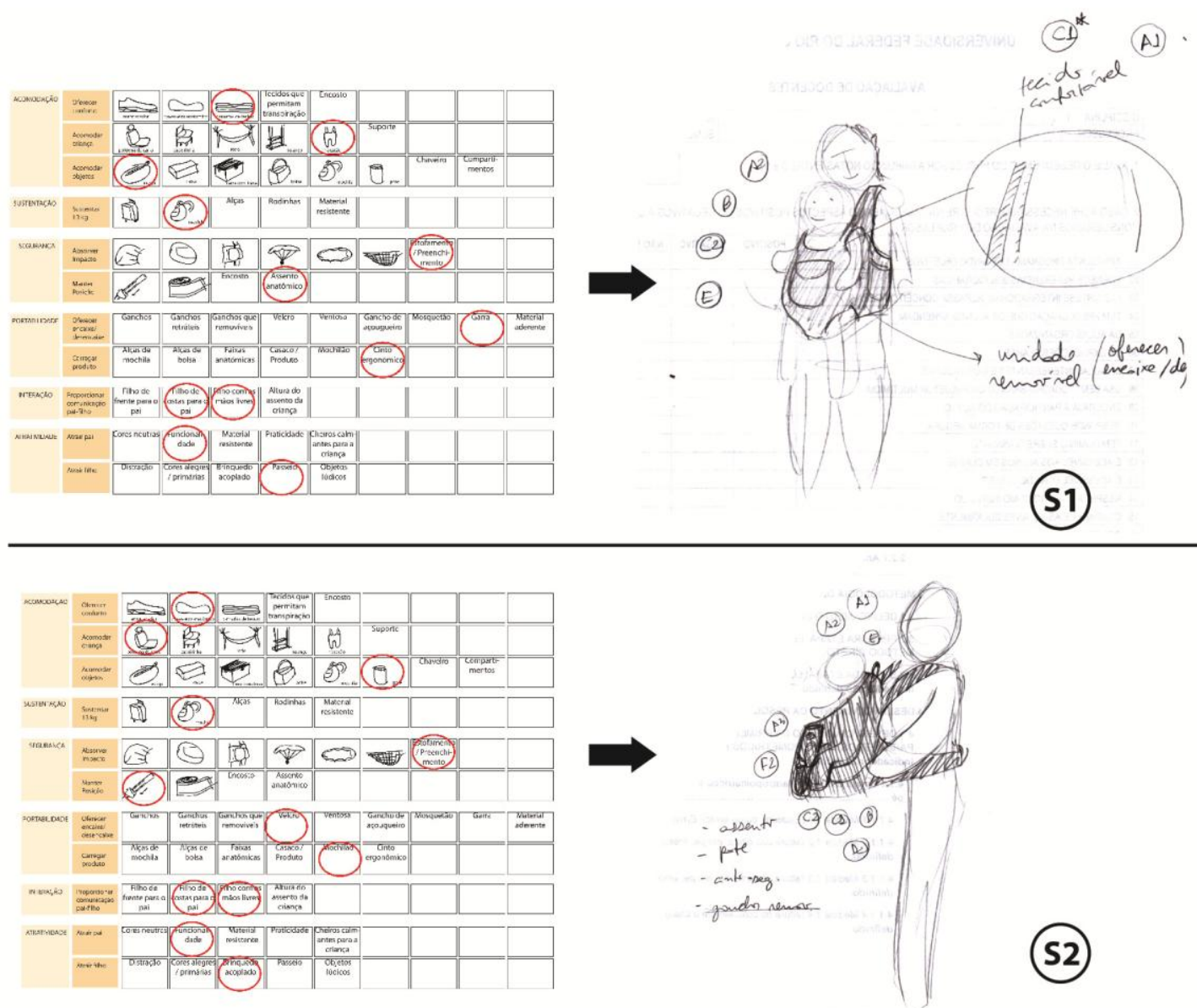

Figura 4 - Concepções S1 e S2.

Fonte: Elaborado pelos autores, com base na pesquisa realizada. 
(53)

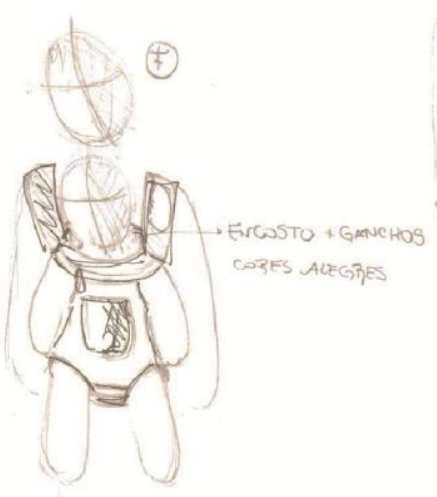

(54)

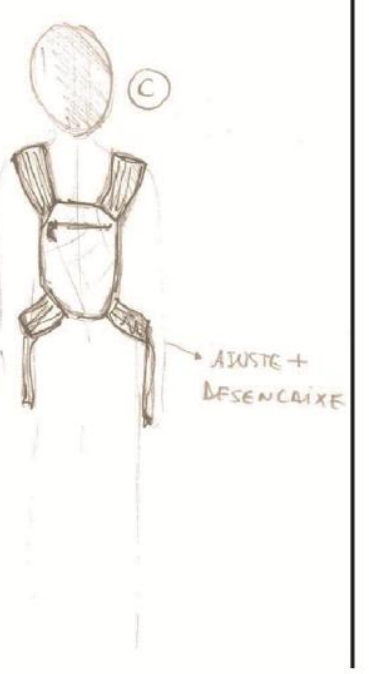

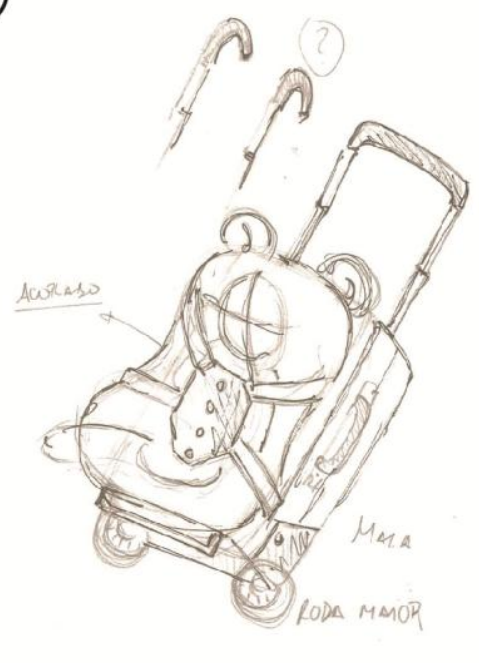

Figura 5 - Concepções S3 e S4

Fonte: Elaborado pelos autores, com base na pesquisa realizada.

\subsection{Seleção das concepções de projeto}

Na seleção das concepções foi utilizado o método de Pugh, que consiste em uma forma sistemática utilizada para a triagem das concepções de projeto. $O$ processo de avaliação se dá através da comparação entre as alternativas geradas e um referencial. Este referencial pode ser um produto similar existente no mercado, uma das alternativas desenvolvidas, um produto concorrente, ou se podem adotar parâmetros limites que diferenciem as soluções viáveis das inviáveis (BACK et al., 2008).

Para este trabalho, foi adotado como referencial um produto similar presente no mercado. O produto escolhido é o modelo Breathe - Vented Comfort Carrier $^{\oplus}$, da marca Infantino, apresentado na Figura 7.

Figura 6 - Produto Referencial.

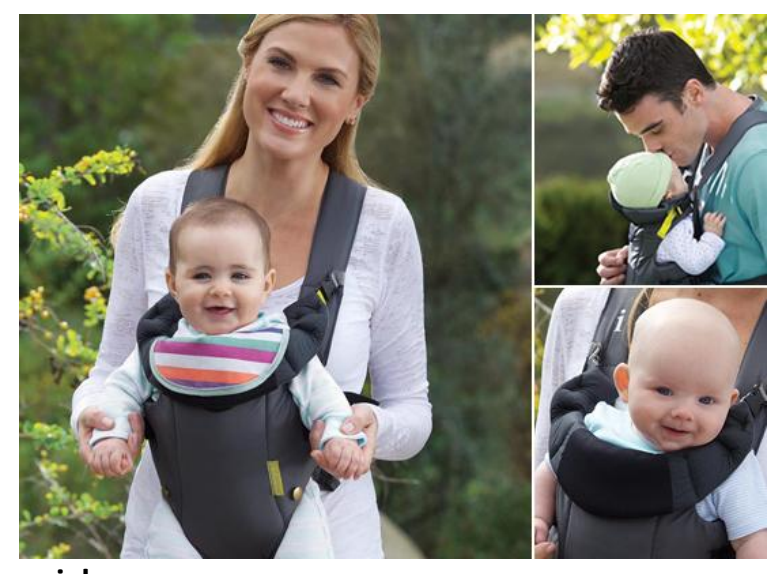

Fonte: web site da empresa Infantino ${ }^{1}$.

A seguir, a Tabela 1 apresenta a matriz de Pugh preenchida de acordo com os requisitos estabelecidos para o produto e o desempenho das soluções desenvolvidas

1 Site da Infantino. Disponível em: <http://infantinoblog.com/category/carriers/>. Acesso em: 10 jun. 2013. 
na etapa anterior. O modelo foi desenvolvido de acordo com Otto e Wood (2001 apud BACK et al., 2008). Na coluna $R$, correspondente ao produto de referência, se registra o valor zero (0). As outras colunas, referentes às alternativas que serão avaliadas, são preenchidas de acordo com a comparação entre a solução avaliada e o produto referencial. Se a alternativa for melhor do que o produto referencial, coloca-se um sinal positivo (+); se for igual se coloca zero (0) e, caso seja pior, assinala-se com um sinal negativo (-).

Tabela 1 - Matriz de Pugh.

\begin{tabular}{lccccc}
\hline Critério & R & S1 & S2 & S3 & S4 \\
\hline Segurança & 0 & + & + & 0 & - \\
Conforto & 0 & + & + & + & + \\
Facilidade de uso/ Montagem/ & 0 & 0 & 0 & 0 & - \\
Desmontagem & & & & & \\
Facilidade de manutenção & 0 & 0 & 0 & 0 & - \\
Boa aparência & 0 & + & + & + & 0 \\
Viabilidade técnica & 0 & - & 0 & 0 & - \\
Baixo custo (custo acessível) & 0 & 0 & 0 & + & - \\
Facilidade de armazenagem & 0 & 0 & - & 0 & - \\
Facilidade de transporte & 0 & + & + & + & - \\
Sustentável & 0 & 0 & 0 & 0 & - \\
\hline RESULTADO & 0 & +3 & +2 & +4 & -7 \\
\hline Fonte: Elaborado pelos autores, com & +3
\end{tabular}

Fonte: Elaborado pelos autores, com base na pesquisa realizada.

Nota-se que as alternativas S1 e S3 obtiveram melhor desempenho em relação às outras concepções e ao modelo referencial. A solução S1 se destacou em relação ao produto referencial nos quesitos segurança, conforto, boa aparência e facilidade de transporte. A solução S3 obteve melhor desempenho nos quesitos conforto, boa aparência, baixo custo e facilidade de transporte. Para dar seguimento às etapas do PDP, as soluções escolhidas no processo de seleção passam para a os processos de modelagem, prototipagem, e testes de uso.

\section{CONSIDERAÇÕES FINAIS}

A aplicação de técnicas criativas para a geração de ideias de produto, assim como na etapa de projeto conceitual, corrobora aos preceitos de Back et al. (2008) e Baxter (2000). Para Baxter (2000) a etapa de projeto conceitual é essencialmente criativa e devem ser geradas tantas concepções quanto for possível. Back et al. (2008) defendem que ainda no planejamento de produtos devem ser geradas inúmeras ideias, pois a cada 100 ideias de produto geradas, apenas 5 tornam-se produtos de sucesso.

O exercício de geração de ideias proporcionado pelo jogo Creative Sketch demonstra-se relevante ao entendimento do processo de projeto e está de acordo com Schön (1983). Segundo sua teoria da reflexão na ação, o melhor caminho para a aprendizagem em projetos é através da ação e, portanto, é possível desenvolver um raciocínio crítico sobre as vantagens de utilizar determinadas técnicas criativas em determinadas situações.

A recomendação de Baxter (2000) a respeito da verificação do espaço problema foi fundamental para auxiliar na geração de concepções de projeto mais adequadas ao 
problema. Além disso, a utilização de um produto de referência auxilia no procedimento de seleção da concepção de projeto. Através deste, podem-se identificar os requisitos de projeto que não são atendidos, evidenciando lacunas no mercado.

Com a realização deste trabalho, pode-se constatar que o emprego do jogo Creative Sketch, bem como, das técnicas sistematizadas complementam-se mutuamente, auxiliando no PDP. O uso destes torna mais eficiente a geração de ideias, geração de conceitos, seleção de concepções e, consequentemente, o atendimento dos requisitos de projeto. Nas fases iniciais de ideação, o jogo Creative Sketch estimula a criatividade das equipes de projeto por meio do uso das técnicas criativas com descontração, humor e competição. Nas fases de geração e seleção de concepções de projeto, o emprego das técnicas sistemáticas da matriz morfológica e do método de Pugh proporciona o desenvolvimento do projeto focado nos requisitos de projeto.

\section{REFERÊNCIAS}

BACK, N.; OGLIARI, A.; DIAS, A.; SILVA, J.C. Projeto integrado de produtos: planejamento, concepção e modelagem. Barueri, SP: Manole, 2008.

BAXTER, Mike R. Projeto de produto: guia prático para o design de novos produtos. 2 a ed. São Paulo: Blucher, 2000.

CARDOZO, Gissele. Proposta de jogo para a solução de problemas não estruturados com a utilização de técnicas criativas. Dissertação (mestrado em design) - Programa de Pós-Graduação em Design, Universidade Federal do Rio Grande do Sul, Porto Alegre, 2012.

COYNE, Richard. Wicked problems revisited. Design Studies, v.26, n. 1, p.5-17, 2005.

CRILLY, Nathan. The Structure of Design Revolutions: Kuhnian Paradigm Shifts in Creative Problem Solving. Design Issues, v.26, n.1, 2010.

CROSS, Nigel. Descriptive models of creative design: application to an example. Design Studies, v.18, 1997.

DORST, Kees; DIJKHUIS, Judith. Comparing paradigms for describing design activity. Design Studies, v.16, n. 2, 1995.

FRIEDMAN, Ken. Creating design knowledge: from research into practice. IDATER 2000 Conference, Loughborough: Loughborough University, 2000.

MADJAR, Nora; ZHENG, Chen; GREENBERG, Ellen. Factors for Radical Creativity, Incremental Creativity, and Routine, Noncreative Performance. Journal of Applied Psychology, v.96, n.4, P. 730-743, 2011.

SANTANA, Suely; ROAZZI, Antonio; DIAS, Maria. Paradigmas do desenvolvimento cognitivo: uma breve retrospectiva. Estudos de Psicologia, v. 11, n. 1, p. 71- 78, jan./jun. 2006.

SCHÖN, Donald. Reflective practitioner: how professionals think in action. New York, EUA: Basic Books, 1983.

SIMON, Herbert. A. The sciences of the artificial. Cambridge, Mass: MIT Press, 1996. SWELLER, John; VON MERRIENBOER, Jeroen; PAAS, Fred. Cognitive architecture and instructional design. Educational Psychology Review, v. 10, n. 3, p. 251-296, 1998. 